\title{
Portfólio no ensino em saúde: contribuição à reflexão a partir de seu uso na disciplina Enfermagem em Doenças Transmissíveis
}

\author{
Portfolio in education in health: contribution to reflection from \\ its use at the discipline Nursing in Communicable Diseases \\ Érica Gomes Pereira ${ }^{1}$, Karen Namie Sakata So ${ }^{1}$, Suely Itsuko Ciosak ${ }^{1}$, Eloá Otrenti ${ }^{1}$, Lúcia Yasuko Izumi Nichiata ${ }^{1}$

DOI: http://dx.doi.org/10.7322/abcshs.v40i3.816

\section{RESUMO}

Introdução: O portfólio acadêmico fornece um acompanhamento contínuo do processo de ensino-aprendizagem e favorece o intercâmbio de percepções sobre atividades teórico-práticas. É tanto um disparador da revisão e problematização do processo de ensino-aprendizagem como também uma ferramenta de avaliação institucional. Relato de experiência: Objetivou-se compartilhar a experiência da utilização do portfólio no ensino da disciplina "Enfermagem em Saúde Coletiva com Enfoque nas Doenças Transmissíveis", do curso de graduação em Enfermagem da Universidade de São Paulo (USP), discutindo potencialidades de seu uso como instrumento para avaliação contínua da aprendizagem. Sua utilização teve início em 2013, para problematizar as experiências pedagógicas em sala de aula e na prática de campo. Em 2015, cada estudante elaborou seu portfólio compondo duas narrativas registradas de forma escrita. Cada tutor acompanhou o mesmo grupo de estudantes do início ao fim da disciplina e analisou o grau de maturidade expressiva alcançado por cada estudante de acordo com a classificação de Sá-Chaves: técnico, crítico ou metacrítico. Nos encontros tutoriais foram problematizados os principais avanços e desafios encontrados pelo estudante, na elaboração, e pelo tutor, na leitura das sínteses de aprendizagem, registradas no portfólio. Conclusão: $O$ portfólio mostra-se um potente instrumento de aprendizagem e seu uso deve ser aprimorado em articulação com a tutoria, prevendo-a como estratégia na estrutura curricular, bem como o tempo e o número de tutores adequado à quantidade de estudantes.

Palavras-chave: estratégias; ensino; prática do docente de enfermagem; educação superior.

\section{ABSTRACT}

Introduction: The academic portfolio provides continuous monitoring of the teaching-learning process and promotes the exchange of insights into theoretical and practical activities. It is both a trigger review and questioning of the teaching-learning process, as well as an institutional assessment tool. Experience report: We aimed to share the experience of using the portfolio in the teaching of discipline "Community Health Nursing with Focus on Infectious Diseases" of the Undergraduate course in Nursing, University of São Paulo (USP), discussing possibilities of its use as a tool for evaluation continuous learning. Its use began in 2013 to discuss the pedagogical experiences in the classroom and on field practice. By 2015, every student has developed its portfolio composing two narratives recorded in writing. Each tutor followed the same group of students from start to finish of the discipline and analyzed the degree of expressive maturity reached by each student according to Sá-Chaves rating: technical, critical or metacritical. In the tutorials meetings were problematized the main advances and challenges encountered by the student in the preparation and the tutor in the learning of reading summaries, registered in the portfolio. Conclusion: The portfolio is shown to be a powerful learning tool and its use should be improved in conjunction with mentoring, predicting it as a strategy in the curriculum, as well as the time and number of suitable tutors the number of students.

Keywords: strategies; teaching; nursing faculty practice; education, higher. 


\section{INTRODUÇÃO}

As universidades brasileiras têm utilizado o portfólio como instrumento pedagógico no ensino de graduação para potencializar a qualificação formativa e enriquecer o aprendizado dos estudantes ${ }^{1,2}$.

Nos cursos da saúde, quem o utiliza afirma que é um dispositivo avaliativo ímpar na construção do conhecimento e no protagonismo dos sujeitos durante a formação profissional ${ }^{3}$. Sua potência está em descrever os diferentes tempos da aprendizagem (sala de aula e mediação com a prática cotidiana do trabalho) e torna visível a transversalidade entre os dois tempos no processo de ensino-aprendizagem. Portanto, promove a ressignificação do conhecimento, potencializa a dimensão subjetiva da aprendizagem, amplia a possibilidade de intervenção dos estudantes, o caráter matricial dos conhecimentos especializados e constrói tecnologias de gestão participativa implicados eticamente com a formação e o protagonismo dos sujeitos ${ }^{4}$.

Em relação à abrangência prática da utilização do portfólio como dispositivo avaliativo, ele pode ser definido como uma ferramenta que possibilita um acompanhamento contínuo do processo individual de ensino-aprendizagem do estudante ao longo de uma disciplina ou um semestre, um ano, entre outros. Quando compartilhado entre os estudantes, o portfólio favorece o intercâmbio de percepções sobre as mediações obtidas nas atividades práticas; é um disparador da problematização acerca dos consensos necessários para revisão dos pactos de ensino-aprendizagem. É também uma ferramenta de avaliação institucional, pois agrega o conjunto dos instrumentos pedagógicos utilizados institucionalmente em parte ou no conjunto do curso para avaliar o aprendizado do estudante ${ }^{3}$.

No ensino superior em Enfermagem, o portfólio tem sido utilizado como um instrumento de aprendizagem que auxilia o estudante a produzir autonomia no processo de aprender de modo crítico e criativo ${ }^{5-11}$.

O presente artigo descreve a experiência da utilização do portfólio no ensino superior da disciplina "A Enfermagem em Saúde Coletiva com Enfoque nas Doenças Transmissíveis", discutindo as potências de seu uso como instrumento para avaliação contínua da aprendizagem.

\section{RELATO DE EXPERIÊNCIA}

A Escola de Enfermagem da Universidade de São Paulo (USP) implementou, em 2010, um projeto político-pedagógico (PPP) no curso de bacharelado cujas disciplinas estão organizadas em três Ciclos ao longo dos quatro anos: Ciclo das Necessidades, Ciclo do Cuidado e Ciclo da Prática Profissional. Cada Ciclo articula-se por meio de eixos integrativos organizados em semestres e módulos. Há ênfase na relação teoria-prática e o oferecimento de maior integração dos conhecimentos aos estudantes, mediante sua inserção nas atividades práticas sob uma tutoria ${ }^{12}$.

No PPP foi prevista a utilização do portfólio como uma estratégia promotora do desenvolvimento do estudante em suas capacidades cognitivas e afetivas, com vistas à aprendizagem significativa e contínua, articulada ao seu projeto de vida e de formação.

A disciplina "A Enfermagem em Saúde Coletiva com Enfoque nas Doenças Transmissíveis" (120 horas) integra o Ciclo Profissional (7o semestre) e vem utilizando o portfólio como instrumento facilitador do processo de ensino-aprendizagem desde 2013.

O referencial teórico adotado pela disciplina na proposta para uso do portfólio baseia-se na pedagogia histórico-crítica, seguindo o método dialético do conhecimento científico que passa da síncrese à síntese pela mediação da análise ${ }^{13}$.

A prática social inicial - que neste relato é o concreto empírico obtido pelo estudante durante a vivência em sala de aula e no campo de estágio - é problematizada para promover a catarse (por meio da síntese escrita do portfólio e da reunião tutorial) para estimular uma prática social reformulada - que neste relato é o concreto pensado obtido pelo estudante ao final da disciplina ${ }^{13}$.

As aulas teóricas tratam de conteúdos em doenças transmissíveis nos âmbitos da assistência individual e coletiva, abordando as ações de prevenção com enfoque na vigilância epidemiológica. As práticas de campo são realizadas no Ambulatório dos Viajantes, Núcleo de Epidemiologia, Ambulatório de Moléstias Infectocontagiosas, Centro de Referência de Imunobiológicos Especiais, que estão alocados no Hospital das Clínicas da Faculdade de Medicina da USP; Centro de Referência em DST/ AIDS, Instituto Clemente Ferreira e Centro de Vigilância Epidemiológica da Secretaria de Estado da Saúde de São Paulo; Hospital Universitário e Centro de Saúde Escola Geraldo Paula Souza, ambos da USP; e as Supervisões de Vigilância em Saúde do Butantã, Sé e Lapa/Pinheiros da Secretaria Municipal da Saúde de São Paulo.

O portfólio busca problematizar as experiências pedagógicas obtidas em sala de aula e em campo de estágio. Na edição de 2015, cada estudante elaborou seu portfólio compondo duas narrativas, registradas na forma escrita, tendo um único tutor durante a disciplina.

A primeira narrativa foi elaborada ao término da primeira semana de aulas teóricas e de prática em campo de estágio, realizada em um dos serviços citados anteriormente, atendendo as seguintes questões norteadoras: "Diante de uma situação vivenciada na primeira semana de estágio, comente as condutas dos sujeitos envolvidos na situação". e "O que você precisa desenvolver para aprofundar os conhecimentos e as habilidades em doenças transmissíveis?". Logo na sequência foi realizada a primeira reunião tutorial com o grupo de sete a oito estudantes.

Por sua vez, a segunda narrativa, solicitada ao final da terceira semana de aulas teóricas e de prática em campo de estágio, teve como foco o relato acerca de habilidades/conhecimentos adquiridos sobre Enfermagem em Doenças Transmissíveis e habilidades/ conhecimentos que são ainda necessários para atuação na assistência/vigilância. Nos encontros tutoriais foram problematizados os principais avanços e desafios encontrados pelo estudante, na 
elaboração, e pelo tutor, na leitura das sínteses de aprendizagem, registradas no portfólio.

Dessa forma, a partir das narrativas, o tutor analisou o grau de maturidade expressiva alcançado por cada estudante, distinto e nominado como técnico, crítico ou metacrítico ${ }^{7}$, adaptado para o ensino da Enfermagem em Saúde Coletiva com Enfoque em Doenças Transmissíveis. A reflexão esperada para o estudante e, consequentemente, as ações esperadas para o tutor na elaboração das sínteses de aprendizagem do portfólio da disciplina podem ser visualizadas no Quadro 1.

\section{DISCUSSÃO}

O portfólio mostrou ser uma ferramenta que possibilita ao estudante a articulação do raciocínio clínico/epidemiológico em relação às doenças transmissíveis na perspectiva da Saúde Coletiva, problematizando práticas articuladas à rede de serviços, pautadas na integralidade da assistência e na vigilância em saúde.

Neste artigo não foram narrados os conteúdos dos portfólios, mas a análise realizada a partir deles, o que possibilitou avaliar a sua utilização. Observou-se empiricamente durante a utilização do portfólio que, apesar da descrição detalhada das situações ocorridas em sala de aula e em campo de estágio, há pouco avanço na inclusão de outros dados na síntese escrita, como, por exemplo, causas e consequências, destacando, nas situações descritas, a incorporação da autorreflexão como elemento proativo no processo

Quadro 1: Reflexão esperada para o estudante e ações esperadas para o tutor na elaboração das sínteses de aprendizagem do portfólio da disciplina

\begin{tabular}{|c|c|c|}
\hline Reflexão & Estudante & Tutor \\
\hline 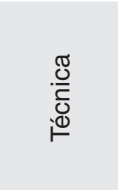 & $\begin{array}{l}\text { Descreve detalhadamente } \\
\text { as situações vivenciadas } \\
\text { na disciplina diante do } \\
\text { conteúdo das doenças } \\
\text { transmissíveis com } \\
\text { enfoque na Saúde Coletiva. }\end{array}$ & $\begin{array}{l}\text { Provoca a capacidade de } \\
\text { problematizar a observação } \\
\text { e estimular a criatividade na } \\
\text { elaboração da síntese de } \\
\text { aprendizagem. }\end{array}$ \\
\hline 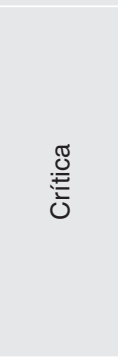 & $\begin{array}{l}\text { Inclui outros elementos } \\
\text { na narrativa, para além } \\
\text { da descrição, como } \\
\text { causas, consequências } \\
\text { e significados percebidos } \\
\text { nos fenômenos a partir da } \\
\text { literatura científica (quem? } \\
\text { o quê? onde? por quê?) }\end{array}$ & $\begin{array}{l}\text { Possibilita a reflexão sobre } \\
\text { o papel dos contextos } \\
\text { (local, regional, municipal, } \\
\text { estadual e/ou federal) } \\
\text { na produção dos fatos } \\
\text { descritos, as funções e os } \\
\text { papéis desempenhados } \\
\text { pelos diferentes sujeitos, as } \\
\text { concepções que sustentam } \\
\text { as decisões que interferem } \\
\text { no contexto observado. }\end{array}$ \\
\hline 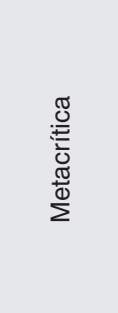 & $\begin{array}{l}\text { Acrescenta a reflexão } \\
\text { detalhada de si mesmo } \\
\text { no processo de } \\
\text { ensino-aprendizagem } \\
\text { pertinente às doenças } \\
\text { transmissíveis com } \\
\text { enfoque na Saúde Coletiva, } \\
\text { desde o primeiro semestre } \\
\text { do curso de bacharelado } \\
\text { em Enfermagem. }\end{array}$ & $\begin{array}{c}\text { Problematiza a atuação, } \\
\text { a compreensão e a } \\
\text { concepção subsumida } \\
\text { à narrativa e aprimora } \\
\text { a aprendizagem do } \\
\text { estudante diante das } \\
\text { doenças transmissíveis } \\
\text { com enfoque na Saúde } \\
\text { Coletiva. }\end{array}$ \\
\hline
\end{tabular}

Fonte: Adaptado de Silva e Sá-Chaves ${ }^{6}$ de ensino-aprendizagem sobre doenças transmissíveis. As limitações podem ser justificadas pela dificuldade dos estudantes e dos tutores em elaborar e analisar as sínteses de aprendizagem, pelo ineditismo da estratégia aplicada às doenças transmissíveis e pela implantação paulatina e heterogênea de novas estratégias avaliativas no curso de bacharelado em Enfermagem da Escola de Enfermagem da USP.

A pouca familiaridade dos tutores e dos estudantes com o uso do portfólio pode ser destacada, principalmente, na fase inicial de implantação dessa ferramenta, notadamente na ausência de narrativas reflexivas aprofundadas e no contraste entre forma e conteúdo durante o uso da expressão verbal e/ou escrita, conforme discutido por outros que já o utilizaram ${ }^{3,11}$.

Relatos de professores de Medicina e de Enfermagem de uma universidade pública do Estado de São Paulo, sobre a utilização do portfólio, salientam que é importante o apoio institucional para a manutenção e ampliação do uso dessa ferramenta a partir da qualificação dos professores e dos estudantes no desenvolvimento da maturidade expressiva esperada em cada reflexão proposta pelas sínteses de aprendizagem que compõem o portfólio ${ }^{6}$.

Ao final da disciplina, os estudantes avaliaram o uso do portfólio como estratégia pedagógica com base no questionamento: "O portfólio da disciplina 'A Enfermagem em Saúde Coletiva com Enfoque nas Doenças Transmissíveis' auxiliou na identificação de avanços no desenvolvimento da sua aprendizagem?". Assim, em relação ao total de 75 estudantes que cursaram a disciplina, 40 (53\%) responderam ao instrumento de avaliação. Destes, 13 $(32,5 \%)$ estudantes avaliaram a estratégia de uso do portfólio como bom e excelente, 16 (40,0\%) consideraram como regular e $11(27,5 \%)$ acharam péssimo e deficiente.

Resultados semelhantes foram encontrados em uma pesquisa realizada com estudantes do curso de Medicina de uma universidade pública do Estado de São Paulo, no qual apesar de a maioria dos estudantes compreender que o portfólio é uma estratégia educacional para a sua formação profissional, poucos o visualizam como uma ferramenta de aprendizagem e consideraram que não havia contribuição no desenvolvimento da sua própria capacidade reflexiva em relação ao conteúdo da disciplina ${ }^{14}$.

A análise do portfólio e a tutoria mostraram que os estudantes têm dificuldade de traduzir suas percepções na narrativa escrita. A expressão verbal observada nas reuniões de tutoria continha maiores detalhes e aprofundamento crítico, quando comparada a alguns registros do portfólio. Um estudo realizado com estudantes do curso de bacharelado em Enfermagem de uma universidade privada do Estado do Rio de Janeiro relata que o maior dilema encontrado na confecção do portfólio é a dificuldade na comunicação escrita dos estudantes quando eles são mobilizados na expressão das suas trajetórias individuais de aprendizado ${ }^{11}$.

Além do conceito atribuído à estratégia, os estudantes registraram suas impressões a respeito do uso do portfólio. As respostas também ficaram distribuídas entre aspectos positivos e negativos da estratégia e das sugestões. Como ponto positivo, os estudantes 
deram destaque ao potencial do portfólio como uma ferramenta que contribui para o desenvolvimento do "senso crítico" do estudante, porque no momento do registro é possível refletir sobre o processo de aprendizagem. Considera-se que a socialização dos avanços e desafios na utilização do portfólio entre os professores em uma disciplina, ou em um semestre, um ano ou um curso, por meio de reuniões periódicas potencializam a pactuação e repactuação de contextos reflexivos esperados para o estudante e estimulados pelo tutor durante a elaboração das sínteses de aprendizagem ${ }^{14,15}$. Entre os pontos destacados pelos estudantes que precisarão ser revistos e readequados estão o esclarecimento do objetivo do portfólio e a sua especificidade e diferenciação com o momento da tutoria.

Os estudantes indicaram a possibilidade de garantir que a produção do portfólio seja um momento de aprendizagem paralelo e complementar, e não sobreposto, aos momentos de tutoria em grupo. Em uma das impressões escritas por estudantes na avaliação da proposta foi solicitado que os tutores façam as devolutivas de forma individual, com apontamentos no material.
Essa sugestão remete à possibilidade de uma integração mais individualizada entre os tutores e os estudantes, deixando o espaço da tutoria para discussões e aprendizados de interesse mútuo, porém, requer disponibilidade maior de carga horária da disciplina, de tempo e do número de tutores. Os desafios impostos na implantação estão, portanto, relacionados aos ajustes institucionais: incompatibilidade entre a proposta pedagógica do portfólio e a estruturação do currículo. $\mathrm{O}$ apoio institucional é outro aspecto a ser considerado para que possa, de fato, utilizar-se do portfólio em sua potência ${ }^{4,11}$. Um estudo aponta a sobrecarga sofrida pelo professor, em turmas com 30 ou mais estudantes, demandando disponibilidade de tempo para o acompanhamento sistemático e o cumprimento da função formativa esperada para o estudante ${ }^{14}$.

Conclui-se que o portfólio pode ser um potente instrumento de aprendizagem e seu uso deve ser aprimorado em articulação com a tutoria, o que requer sua inclusão como estratégia na estrutura curricular, bem como tempo e número de tutores adequado ao número de estudantes.

\section{REFERÊNCIAS}

1. Ambrósio M. O uso do portfólio no ensino superior. São Paulo: Vozes; 2013

2. Albertino FMF, Souza NA. Avaliação da aprendizagem: o portfólio como auxiliar na construção de um profissional reflexivo. Est Aval Educ. 2004;(29):169-89

http://dx.doi.org/10.18222/eae02920042164

3. Ferla AA, Ceccim RB. Portfólio como dispositivo da avaliação: aproximações para a definição de novas estratégias de avaliação no curso de bacharelado em Saúde Coletiva da UFRGS. In: Ferla AA, Rocha CMF. Cadernos da Saúde Coletiva: inovações na formação de sanitaristas. Porto Alegre: Rede Unida; 2013

4. Ferla AA, Bertele E, De David M, Batista MV. O portfólio avaliativo como dispositivo para a gestão de processos de educação permanente em saúde. $8^{\circ}$ Congresso da Rede Unida; 2009.

5. Rezende KTA, Takeda E, Fraga EMV, Braccialli LAD, Chirelli $M Q$, Costa MCG, et al. Implementing educational program for Famema's nursing course: reporting the experience. Interface. 2006;10(20):525-35

http://dx.doi.org/10.1590/S1414-32832006000200018

6. Silva RF, Sá-Chaves I. Formação reflexiva: representações dos professores acerca do uso de portfólio reflexivo na formação de médicos e enfermeiros. Interface. 2008;12(27):721-34. http://dx.doi.org/10.1590/S1414-32832008000400004

7. Friedrich DBC, Gonçalves AMC, Sá TS, Sanglard LR, Duque DR, Oliveira GMA. O portfólio como avaliação: análise de sua utilização na enfermagem. Rev Latino-Am Enferm. 2010; 18(6):1123-30

http://dx.doi.org/10.1590/S0104-11692010000600012
8. Sordi MRL, Silva MM. O uso de portfólios na pedagogia universitária: uma experiência em cursos de enfermagem. Interface. 2010;14(35):943-53.

http://dx.doi.org/10.1590/S1414-32832010005000018

9. Fortuna CM, Goncalves MFC, Silva MAI, Santos RA. A produção de narrativas crítico-reflexivas nos portfólios de estudantes de enfermagem. Rev Esc Enferm USP. 2012;46(2):452-9. http://dx.doi.org/10.1590/S0080-62342012000200025

10. Vaz DR, Prado C. Prática pedagógica reflexiva de licenciados de enfermagem: o portfólio como instrumento. Rev Esc Enferm USP. 2014;48(6):1103-10.

http://dx.doi.org/10.1590/S0080-623420140000700019

11. Tanji S, Silva CMSLMD. As potencialidades e fragilidades do portfólio reflexivo na visão dos estudantes de enfermagem. Rev Enf UERJ. 2008;16(3):392-8.

12. Oliveira MAC, Verissimo MDLR, Puschel VA, Riesco MLG. Desafios da formação em enfermagem no Brasil: proposta curricular da EEUSP para o bacharelado em enfermagem. Rev Esc Enferm USP. 2007;41(N.Esp.):820-5. http://dx.doi.org/10.1590/S0080-62342007000500014

13. Saviani D. Pedagogia histórico-crítica: primeiras aproximações Campinas: Autores Associados; 2005

14. Silva RF, Francisco MA. Portfólio reflexivo: uma estratégia para a formação em medicina. Rev Bras Educ Med. 2009;33(4):562-70. http://dx.doi.org/10.1590/S0100-55022009000400007

15. Rangel JNM, Nunes LC, Garfinkel M. O portfólio no ensino superior: práticas avaliativas em diferentes ambientes de aprendizagem. Proposições. 2006;17(3):167-80 